\title{
Down Regulation of miR-34a and miR-143 May Indirectly Inhibit p53 in Oral Squamous Cell Carcinoma: a Pilot Study
}

\author{
Mayakannan Manikandan ${ }^{1 \&}$, Arunagiri Kuha Deva Magendhra Rao ${ }^{1 \&}$, Ganesan \\ Arunkumar ${ }^{1}$, Kottayasamy Seenivasagam Rajkumar' ${ }^{2}$ Ramamurthy Rajaraman $^{2}$, \\ Arasambattu Kannan Munirajan ${ }^{1 *}$
}

\begin{abstract}
Background: Aberrant microRNA expression has been associated with the pathogenesis of a variety of human malignancies including oral squamous cell carcinoma (SCC). In this study, we examined primary oral SCCs for the expression of 6 candidate miRNAs, of which five (miR-34a, miR-143, miR-373, miR-380-5p, and miR504) regulate the tumor suppressor TP53 and one (miR-99a) is involved in AKT/mTOR signaling. Materials and Methods: Tumor tissues (punch biopsies) were collected from 52 oral cancer patients and as a control, 8 independent adjacent normal tissue samples were also obtained. After RNA isolation, we assessed the mature miRNA levels of the 6 selected candidates against RNU44 and RNU48 as endogenous controls, using specific TaqMan miRNA assays. Results: miR-34a, miR-99a, miR-143 and miR-380-5p were significantly down-regulated in tumors compared to controls. Moreover, high levels of miR-34a were associated with alcohol consumption while those of miR-99a and miR-143 were associated with advanced tumor size. No significant difference was observed in the levels of miR-504 between the tumors and controls whereas miR-373 was below the detection level in all but two tumor samples. Conclusions: Low levels of miR-380-5p and miR-504 that directly target the 3'UTR of TP53 suggest that p53 may not be repressed by these two miRNAs in OSCC. On the other hand, low levels of miR-34a or miR-143 may relieve MDM4 and SIRT1 or MDM2 respectively, which will sequester p53 indicating an indirect mode of $\mathbf{p 5 3}$ suppression in oral tumors.
\end{abstract}

Keywords: MicroRNAs (miRNA) - oral squamous cell carcinoma - head and neck cancer - tumor protein 53

Asian Pac J Cancer Prev, 16 (17), 7619-7625

\section{Introduction}

Oral squamous cell carcinoma (OSCC) is one of the major public health problems and is the sixth common human malignancy worldwide (Parkin et al., 2005). However, in India, it is the leading cancer in males and ranks within the top 5 malignancies in females (Dikshit et al., 2012; Ferlay et al., 2015). Characterization of the somatic mutational landscape of OSCC either alone or together with other head and neck neoplasms has revealed that TP53 is the most commonly mutated gene (Agrawal et al., 2011; Stransky et al., 2011; India Project Team of the International Cancer Genome, 2013; Pickering et al., 2013). The p53 protein, encoded by the TP53 gene, has a pivotal role in tumor suppression and is a mainstay of intrinsic anticancer defence systems. Its importance is reflected in the popular name "guardian of the genome" (Lane, 1992). Besides genetic mutation, the function and expression of p53 is controlled at several levels including transcription, post-transcriptional modification etc.
Recently, microRNA (miRNA) mediated gene silencing was also described to attenuate p53 expression (Feng et al., 2011).

MicroRNAs (miRNAs) are 17- to 23-nucleotides, short, non-coding RNA molecules that negatively regulate gene expression at post-transcriptional level (Bartel, 2009). Mammalian miRNAs are versatile as a complementarity between the nucleotides spanning the position 2 to 7 of 5' end (known as miRNA 'seed') and the 3' untranslated region (3'UTR) of target mRNAs is enough for effective gene silencing. Thus, a single miRNA can target hundreds of mRNA and the 3'UTR of a single mRNA can be targeted by several miRNAs (Lewis et al.,2005). Based on this principle, computational approximations suggest that nearly half of all protein coding genes are regulated by miRNAs (Friedman et al., 2009), and therefore miRNAs participate in all vital cellular functions (Bushati and Cohen, 2007). As a consequence, deregulation in functioning or expression of miRNAs has been well-documented to result in a variety 
of human diseases, especially cancer, wherein miRNA themselves are known to function as oncogenes and tumor suppressors (Nelson and Weiss, 2008; Shiiba et al., 2010; Nohata et al., 2013). Several previous publications has substantiated the involvement of miRNAs in the pathogenesis of OSCC, and a compendium of miRNAs were shown to be differentially expressed (Chang et al., 2008; Chen et al., 2013). However, there has been limited research in OSCC on miRNAs that regulate or are regulated by TP53. Moreover, TP53 mutations were reported to be less frequent in Indian OSCC cases, when compared to the rest of the world (Kannan et al., 1999; Saranath et al., 1999; Zanaruddin et al., 2013), opening up the possibility of exploring the other dimensions of p53 inactivation.

In view of the above, we selected six candidate miRNAs among which hsa-miR-380-5p and hsamiR-504 are known to directly suppress the translation of TP53 mRNA by targeting its 3' UTR (Hu et al., 2010; Swarbrick et al., 2010), while hsa-miR-34a, hsa-miR-143 and hsa-miR-373 indirectly regulate p53 activity by the respective targeting of SIRT1 and MDM4, MDM2, and LATS2 (Aylon et al., 2006; Yamakuchi et al., 2008; Lee et al., 2009; Mandke et al., 2012; Zhang et al., 2013a). Additionally, hsa-miR-143 and hsa-miR-34a are direct transcriptional targets of p53 (Chang et al., 2007; RaverShapira et al., 2007; Zhang et al., 2013a). The other candidate, hsa-miR-99a, known for its involvement in the regulation of AKT/mTOR signaling pathway (Chen et al., 2012), is independent of the p53 pathway. However, a connection between the p53 and AKT/mTOR signaling pathway has been previously established (Feng et al., 2005; Levine et al., 2006). A schematic illustration of how the selected miRNAs are linked to p53 is presented in Figure 1.

\section{Materials and Methods}

The present study was approved by the Ethical Review Board of Government Royapettah Hospital, Chennai (Letter No.371/RMO/2010 dt.29.1.2010) and was conducted within the ethical framework of Dr. ALM PG Institute of Basic Medical Sciences, Chennai. Informed consent forms were signed by all participants.

\section{Subjects}

Fifty two OSCC tissue samples and 8 independent normal tissues were collected from patients of Government Royapettah Hospital, Chennai. The patients' background and clinico-pathological characteristics were documented in a standard questionnaire. The tumor specimens were collected under local anesthesia with a 3-mm punch biopsy, immersed in RNAlater solution (Ambion, Austin, TX, USA) and transported to laboratory in cold-storage container. In case of control tissues, biopsies were punched $2 \mathrm{~cm}$ away from the tumor margins. It should be noted that either the tumor tissue or the control tissue were excised from a patient but not both, according to the patient's will and consent. The tissues were minced into smaller pieces and RNAlater was allowed to percolate for a day at $4^{\circ} \mathrm{C}$. On the subsequent day, RNAlater was drained off and tissues were stored at $-80^{\circ} \mathrm{C}$ until RNA extraction.

\section{RNA isolation}

Homogenization of tissue samples were carried out in a MicroSmash MS-100 automated homogenizer (Tomy, Japan) with Zirconium beads, followed by RNA isolation with miRNeasy kit (Qiagen, Germany) according to the manufacturer's protocol and instructions. The quantity and quality of the extracted RNA was checked by spectrophotometry (Nanodrop 2000, Thermo Fisher Scientific Inc., USA) and samples of optical density higher than 1.9 at 260/280 $\mathrm{nm}$ were used for further reverse transcription.

\section{Two-step reverse transcription quantitative PCR}

Reverse transcription quantitative PCR (RT-qPCR) was performed using TaqMan MicroRNA Reverse transcription kit and TaqMan miRNA assays (Table 1), following the manufacturer's protocol. All reagents were obtained from Applied Biosystems (USA) and the experiments were carried out in a 7500HT Real Time PCR System. cDNA was synthesized in a $15 \mu \mathrm{L}$ total volume containing $100 \mathrm{mM}$ dNTPs, Multiscribe Reverse Transcriptase (50 U/ $\mu \mathrm{L})$, RT buffer, RNase inhibitor, RNA sample $(10 \mathrm{ng} / 15 \mu \mathrm{L})$ and specific $5 \mathrm{X}$ TaqMan microRNA RT primers. After reverse transcription, the products were diluted 15 times, added to 384 well optical plates and RT-qPCR reactions (in triplicates) were performed in a $10 \mu \mathrm{L}$ total volume containing the required proportion of TaqMan 2X Universal Master Mix (No AmpErase UNG) and specific 20X TaqMan MicroRNA assay. A negative control without cDNA was also included in parallel. RNU44 and RNU48 were used as endogenous references. Expression fold changes were computed using the 2$\Delta \Delta C t$ calculation (Livak and Schmittgen, 2001), where

$\Delta \mathrm{C}_{\mathrm{t}}=\mathrm{C}_{\mathrm{t}}$ (test miRNA) $-\mathrm{C}_{\mathrm{t}}$ (average of RNU44 and RNU48) and $\Delta \Delta \mathrm{C}_{\mathrm{t}}=\Delta \mathrm{C}_{\mathrm{t}}$ (individual sample) $-\Delta \mathrm{C}_{\mathrm{t}}$ (control median)

\section{Statistical analyses}

Statistical analyses of the data were carried out in GraphPad Prism 6 (GraphPad software Inc., La Jolla, CA, USA). The fold change ratios of each miRNA in the samples were $\log 2$ transformed and tested for normality by the Kolmogorov-Smirnov test. In case of Gaussian distribution (miR-99a, miR-143 and miR-504), the difference between the two groups were analysed using Student's t-test. Whenever, a significant difference in variance was observed between the groups, a Welch correction was applied post t-test (miR-504, miR-99a). In case of non-Gaussian distribution (miR-34a and miR380-5p), Mann Whitney test for independent samples was applied. The expression of each miRNA in tumors was further tested for association with the clinico-pathological characteristics by means of Student's t-test or Mann Whitney test in case of two subgroups, and by One-way ANOVA or Kruskal-Wallis test in case of more than two subgroups. All tests were two tailed and a $\mathrm{P}<0.05$ was considered as significant. The relative expression levels are provided as mean or median as and when applicable. 
Down Regulation of miR-34a and miR-143 May Indirectly Inhibit p53 in Oral Squamous Cell Carcinoma: a Pilot Study

Table 1. Details of Candidate miRNAs Selected for Evaluation

\begin{tabular}{|c|c|c|c|}
\hline Assay ID* & Assay Name & miRBase ID & Sequence \\
\hline 426 & hsa-miR-34a & hsa-miR-34a-5p & UGGCAGUGUCUUAGCUGGUUGU \\
\hline 435 & hsa-miR-99a & hsa-miR-99a-5p & AACCCGUAGAUCCGAUCUUGUG \\
\hline 2249 & hsa-miR-143 & hsa-miR-143-3p & UGAGAUGAAGCACUGUAGCUC \\
\hline 561 & hsa-miR-373 & hsa-miR-373-3p & GAAGUGCUUCGAUUUUGGGGUGU \\
\hline 570 & hsa-miR-380-5p & hsa-miR-380-5p & UGGUUGACCAUAGAACAUGCGC \\
\hline 2084 & hsa-miR-504 & hsa-miR-504-5p & AGACCCUGGUCUGCACUCUAUC \\
\hline 1094 & RNU44 & NR_002750\# & $\begin{array}{r}\text { CCTGGATGATGATAGCAAATGCTGACTGAACATGAA } \\
\text { GGTCTTAATTAGCTCTAACTGACT }\end{array}$ \\
\hline 1006 & RNU48 & NR_002745\# & $\begin{array}{r}\text { GATGACCCAGGTAACTCTGAGTGTGTCGCTGATGCCA } \\
\text { TCACCGCAGCGCTCTGACC }\end{array}$ \\
\hline
\end{tabular}

*All assay IDs follow the Inventoried catalog no. 4427975. \# NCBI Accession number

Table 2. Consolidated Clinico-pathological Profile of Fifty two Oral Cancer Patients

\begin{tabular}{|c|c|}
\hline Clinico-pathological characteristics & No. of Patients (\%) \\
\hline \multicolumn{2}{|l|}{ Gender } \\
\hline Male & $35(67.31)$ \\
\hline Female & $17(32.69)$ \\
\hline Mean Age & 2.73 (range $32-86)$ \\
\hline \multicolumn{2}{|l|}{ Tumor sites } \\
\hline Gingivo-buccal complex & $44(84.62)$ \\
\hline Tongue & $8(15.38)$ \\
\hline \multicolumn{2}{|l|}{ Pathological Stage } \\
\hline II & $4(07.69)$ \\
\hline III & $8(15.38)$ \\
\hline IV & $39(75.00)$ \\
\hline Status unknown & $1(01.92)$ \\
\hline \multicolumn{2}{|l|}{ Lymph Node Involvement } \\
\hline Negative (N0) & $6(11.54)$ \\
\hline Positive $(\mathrm{N}+)$ & $45(86.54)$ \\
\hline Status unknown & $1(01.92)$ \\
\hline \multicolumn{2}{|l|}{ Pathological Grade } \\
\hline Well & $12(23.08)$ \\
\hline Moderate & $28(53.58)$ \\
\hline Poor & $12(23.08)$ \\
\hline \multicolumn{2}{|l|}{ Habit profile } \\
\hline Exclusive Chewers & $10(19.23)$ \\
\hline Exclusive Smokers & $13(25.00)$ \\
\hline Exclusive Drinkers & $1(01.92)$ \\
\hline Mix habitué's* & $20(38.46)$ \\
\hline None & $8(15.38)$ \\
\hline
\end{tabular}

\section{Results}

\section{Patient characteristics}

The clinico-pathological characteristics of the 52 oral cancer patients included in this study are summarized in Table 2. The age of the patients ranged from 32 to $86 \mathrm{yrs}$. with a mean of $52.7 \mathrm{yrs}$. There were a higher proportion of males $(67.3 \%)$ than females $(32.7 \%)$. Gingivo-buccal complex was the most common site of tumor occurrence $(84.6 \%)$, which is related to the chewing of various tobacco products. Most of the patients presented with advanced TNM stage (90.4\%) and $86.5 \%$ were positive for regional lymph node involvement. Predominantly, tumors were of moderately differentiated histology (53.85\%).

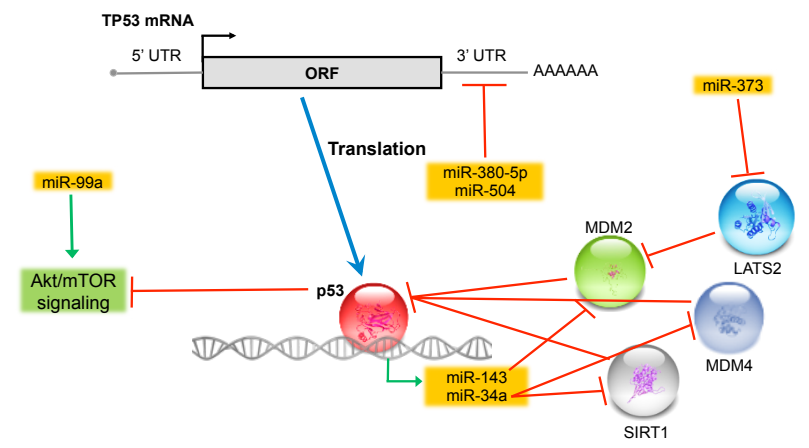

Figure 1. Regulation of p53 Activity by the MicroRNAs Selected for Evaluation in the present study. The microRNAs miR-380-5p and miR-504 directly target the 3' untranslated region (3'UTR) of TP53 mRNA and suppresses its translation, while miR-34a, miR-143 and miR-373 indirectly regulate p53 activity by targeting SIRT1and MDM4, MDM2, and LATS2, respectively. Additionally, miR-143 and miR-34a are under the transcriptional control of $\mathrm{p} 53$. The candidate miR99a activates AKT/mTOR signaling pathway and p53 is known to repress this pathway in response to various stress signals

Approximately $85 \%$ of the patients had practiced at least one of the behavioral risk habits associated with OSCC.

\section{The relative expression of microRNAs in oral tumors}

We examined the expression of the 6 candidate miRNAs in OSCC samples $(n=52)$ compared to independent adjacent normal tissues $(n=8)$ using TaqMan probes (Applied Biosystems, USA). Two smallnucleolar RNAs namely RNU44 and RNU48 were used as endogenous references for normalization. Statistical analyses of the data obtained from RT-qPCR showed that the expression of four miRNAs were significantly low in OSCC sample group compared to controls (Figure 2). These are hsa-miR-34a (0.39 in tumor Vs 1.01 in control; $\mathrm{P}=0.0007)$, hsa-miR-99a (0.27 in tumor Vs 1.16 in control; $\mathrm{P}=0.0219)$, hsa-miR-143 (0.46 in tumor Vs 1.07 in control; $\mathrm{P}=0.0146)$ and hsa-miR-380-5p (0.04 in tumor Vs 1.03 in control; $\mathrm{P}=0.0071$ ). Hsa-miR-504, despite its down regulation in tumors, was not statistically significant $(0.46$ in tumor Vs 1.86 in control; $\mathrm{P}=0.0896)$. The $\mathrm{Ct}$ value for hsa-miR-373 was undetermined in all controls and tumors except for two OSCC specimens. This indicates that miR373 expression is either below the detection limit or is not 
expressed at all in the oral cavity.

Association with clinico-pathological characteristics

The relative fold change of miRNAs in tumors is merely an overall estimate and it should be noted that the tumor samples differ with respect to their pathological stage, grade etc. Therefore, we sub-classified the tumors based on their clinical parameters and tested their association with miRNA expression levels by univariate analysis (Table 3). Interestingly, miR-34a was associated with histological grade and alcohol consumption status. High levels of miR-99a and miR-143 were associated with advanced tumor size (T3-T4). Since miR-373 was expressed in only two of the OSCC samples, we could not test its association with the tumor characteristics. Of note, these two samples were female buccal mucosal tissue samples of advanced tumor stage (IVa) with involvement of a single/multiple ipsilateral lymph node(s) i.e., N2a or $\mathrm{N} 2 \mathrm{~b}$.

\section{Discussion}

MicroRNAs play a pivotal role in an array of physiological functions and consequently miRNA deregulation has been linked to various diseases. Recently, this class of non-coding RNAs have been extensively investigated in various cancers including OSCC. However, on account of the limited research in OSCC on miRNAs

Table 3. Association of miRNA levels with clinico-pathological characteristics of oral tumors

\begin{tabular}{|c|c|c|c|c|c|c|}
\hline Variable & Category & $\begin{array}{r}\text { miR-34a } \\
\text { median (range) }\end{array}$ & $\begin{array}{r}\operatorname{miR}-99 a \\
\text { mean } \pm \text { SD }\end{array}$ & $\begin{array}{r}\text { miR-143 } \\
\text { mean } \pm \text { SD }\end{array}$ & $\begin{array}{r}\text { miR-380-5p } \\
\text { median (range) }\end{array}$ & $\begin{array}{r}\operatorname{miR}-504 \\
\text { mean } \pm \text { SD }\end{array}$ \\
\hline \multicolumn{7}{|l|}{ Age } \\
\hline & $<60$ & $0.41(0.17-1.87)$ & $0.24 \pm 0.20$ & $0.42 \pm 0.33$ & $0.05(0.02-2.27)$ & $0.48 \pm 1.06$ \\
\hline & $\geq 60$ & $0.31(0.14-2.93)$ & $0.33 \pm 0.50$ & $0.56 \pm 0.97$ & $0.04(0.02-4.85)$ & $0.42 \pm 0.63$ \\
\hline & P-value & 0.15 & 0.46 & 0.56 & 0.23 & 0.79 \\
\hline \multicolumn{7}{|l|}{ Gender } \\
\hline & Male & $0.41(0.16-2.93)$ & $0.28 \pm 0.34$ & $0.50 \pm 0.69$ & $0.05(0.02-4.85)$ & $0.42 \pm 0.77$ \\
\hline & Female & $0.34(0.14-1.87)$ & $0.25 \pm 0.29$ & $0.39 \pm 0.41$ & $0.03(0.02-2.27)$ & $0.55 \pm 1.22$ \\
\hline & $P$-value & 0.4 & 0.79 & 0.46 & 0.28 & 0.7 \\
\hline \multicolumn{7}{|c|}{ Anatomical site } \\
\hline & GBC & $0.37(0.14-2.93)$ & $0.27 \pm 0.35$ & $0.47 \pm 0.65$ & $0.04(0.02-4.85)$ & $0.49 \pm 1.00$ \\
\hline & Tongue & $0.47(0.17-0.94)$ & $0.25 \pm 0.17$ & $0.46 \pm 0.30$ & $0.12(0.03-1.51)$ & $0.27 \pm 0.32$ \\
\hline & P-value & 0.36 & 0.89 & 0.96 & 0.39 & 0.24 \\
\hline \multicolumn{7}{|c|}{ Clinical stage } \\
\hline & I or II & $0.39(0.19-0.63)$ & $0.21 \pm 0.06$ & $0.30 \pm 0.22$ & $0.05(0.03-0.06)$ & $1.11 \pm 1.86$ \\
\hline & III or IV & $0.56(0.14-2.93)$ & $0.27 \pm 0.34$ & $0.47 \pm 0.63$ & $0.46(0.02-4.85)$ & $0.41 \pm 0.84$ \\
\hline & & 0.81 & 0.36 & 0.59 & 0.92 & 0.5 \\
\hline \multicolumn{7}{|c|}{ Tumor Size } \\
\hline & $\mathrm{T} 1$ or $\mathrm{T} 2$ & $0.37(0.17-0.77)$ & $0.14 \pm 0.09$ & $0.25 \pm 0.16$ & $0.05(0.03-0.63)$ & $0.58 \pm 1.35$ \\
\hline & $\mathrm{T} 3$ or $\mathrm{T} 4$ & $0.39(0.14-2.93)$ & $0.29 \pm 0.35$ & $0.50 \pm 0.66$ & $0.04(0.02-4.85)$ & $0.44 \pm 0.87$ \\
\hline & $P$-value & 0.44 & 0.03 & 0.04 & 0.96 & 0.71 \\
\hline \multicolumn{7}{|c|}{ Nodal invasion } \\
\hline & $\mathrm{N}+$ & $0.39(0.14-2.93)$ & $0.27 \pm 0.35$ & $0.47 \pm 0.65$ & $0.04(0.02-4.85)$ & $0.42 \pm 0.85$ \\
\hline & N- & $0.38(0.19-0.98)$ & $0.20 \pm 0.08$ & $0.36 \pm 0.25$ & $0.06(0.03-1.23)$ & $0.77 \pm 1.54$ \\
\hline & P-value & 0.87 & 0.27 & 0.44 & 0.31 & 0.61 \\
\hline \multicolumn{7}{|c|}{ Histological grade } \\
\hline & G1/well & $0.28(0.17-0.94)$ & $0.18 \pm 0.14$ & $0.30 \pm 0.29$ & $0.06(0.02-1.51)$ & $0.44 \pm 1.09$ \\
\hline & G2/moderate & $0.45(0.16-2.93)$ & $0.31 \pm 0.38$ & $0.55 \pm 0.67$ & $0.05(0.02-4.29)$ & $0.49 \pm 1.00$ \\
\hline & G3/poor & $0.37(0.14-2.85)$ & $0.24 \pm 0.33$ & $0.42 \pm 0.68$ & $0.03(0.02-4.85)$ & $0.41 \pm 0.59$ \\
\hline & $P$-value & 0.04 & 0.48 & 0.48 & 0.27 & 0.96 \\
\hline \multicolumn{7}{|l|}{ Smoking } \\
\hline & Yes & $0.41(0.16-2.85)$ & $0.24 \pm 0.22$ & $0.44 \pm 0.46$ & $0.05(0.02-4.85)$ & $0.47 \pm 0.82$ \\
\hline & No & $0.34(0.14-2.93)$ & $0.30 \pm 0.45$ & $0.50 \pm 0.80$ & $0.03(0.02-4.29)$ & $0.44 \pm 1.11$ \\
\hline & P-value & 0.44 & 0.59 & 0.78 & 0.14 & 0.91 \\
\hline \multicolumn{7}{|c|}{ Tobacco chewing } \\
\hline & Yes & $0.42(0.14-2.85)$ & $0.26 \pm 0.27$ & $0.47 \pm 0.53$ & $0.04(0.02-4.85)$ & $0.37 \pm 0.61$ \\
\hline & No & $0.35(0.16-2.93)$ & $0.27 \pm 0.37$ & $0.46 \pm 0.68$ & $0.04(0.02-4.29)$ & $0.53 \pm 1.13$ \\
\hline & $P$-value & 0.17 & 0.93 & 0.92 & 0.86 & 0.53 \\
\hline \multicolumn{7}{|c|}{ Alcohol intake } \\
\hline & Yes & $0.46(0.21-2.85)$ & $0.28 \pm 0.26$ & $0.51 \pm 0.55$ & $0.05(0.03-4.85)$ & $0.42 \pm 0.66$ \\
\hline & No & $0.33(0.14-2.93)$ & $0.26 \pm 0.36$ & $0.44 \pm 0.64$ & $0.04(0.02-4.29)$ & $0.48 \pm 1.07$ \\
\hline & $P$-value & 0.02 & 0.77 & 0.7 & 0.25 & 0.81 \\
\hline \multicolumn{7}{|c|}{ Risk habits (combined) } \\
\hline & Any risk habit & $0.39(0.14-2.85)$ & $0.24 \pm 0.21$ & $0.41 \pm 0.41$ & $0.04(0.02-4.85)$ & $0.38 \pm 0.72$ \\
\hline & None & $0.34(0.19-2.93)$ & $0.44 \pm 0.68$ & $0.78 \pm 1.23$ & $0.05(0.02-4.29)$ & $0.87 \pm 1.71$ \\
\hline & $P$-value & 0.69 & 0.43 & 0.43 & 0.91 & 0.46 \\
\hline
\end{tabular}

*SD, Standard deviation; GBC, Gingivo-buccal complex. Bold faceted are the significant P-values $(<0.05)$ 
(a)

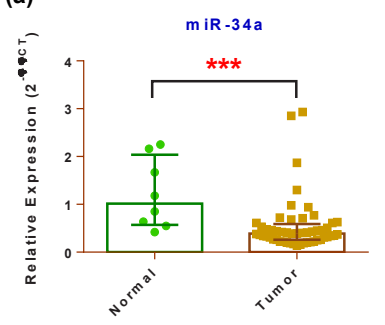

(c)

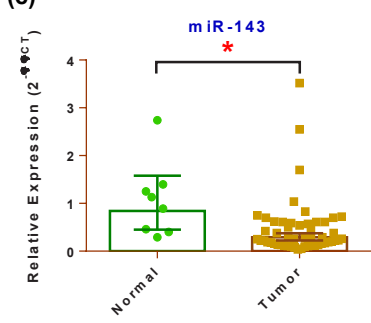

(e)

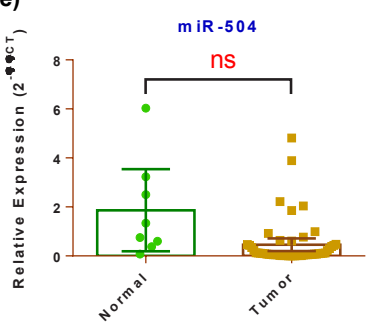

(b)

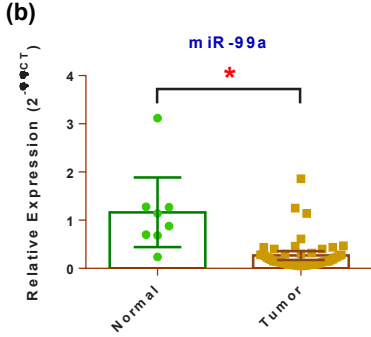

(d)

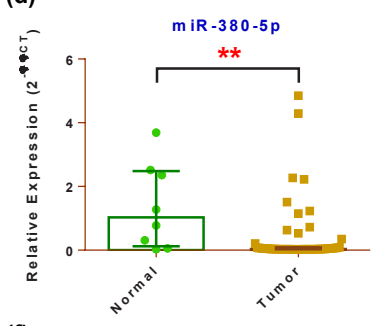

(f)

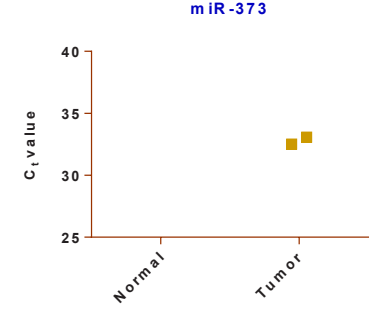

Figure 2. The Differential Expression of Candidate miRNAs in Oral Cancer and Control Samples. Box and whisker plots representing the expression of (a) miR-34a, (b) miR-99a, (c) miR-143, (d) miR-380-5p and (e) miR-504 in OSCC specimens $(n=52)$ and independent adjacent normal tissues $(n=8)$. Error bars of (a) and (d) represents median and interquartile range while that of (b), (c) and (e) represent mean and $95 \%$ confidence limits. The solid black circles and squares represent the miRNA expression values in individual samples of control and tumor, respectively. *,** and $* * *$ represent statistical significance at $\mathrm{P}<0.05, \mathrm{P}<0.01$ and $\mathrm{P}<0.001$, respectively. 'ns' represents $\mathrm{P}=$ not significant. In (f), the Ct value of miR-373 in OSCC and control specimens as detected by RT-qPCR is shown

that regulate or is regulated by $\mathrm{p} 53$, we undertook this study. Several miRNAs have been identified to regulate p53 either directly by binding its 3' UTR or indirectly by targeting p53 modifying enzymes (Hermeking, 2012). We chose miR-380-5p and miR-504 among the direct p53 regulators, miR-34a, miR-143 and miR-373 among the indirect p53 regulators, and miR-99a that is independent of the p53 pathway.

The miRNAs miR-380-5p and miR-504 are suggested oncomiRs since each miRNA binds to two different sites in the 3'UTR of TP53 and inhibits its translation (Hu et al., 2010; Swarbrick et al., 2010). Indicative of its oncogenic nature, high expression of miR-380$5 \mathrm{p}$ correlated with poor outcome in neuroblastomas showing MYCN amplification and further cooperated with activated RAS to transform primary cells, block oncogene-induced senescence and form tumors in mice (Swarbrick et al., 2010). Similarly, overexpression of miR-504 caused a decrease in p53 protein levels leading to tumor progression (Hu et al., 2010). A previous study in OSCC demonstrated that over expression of miR-504 resulted in down regulation of FOXP1 and contributed to

invasion (Yang et al., 2012). However, the expression of these two miRNAs tend to vary based on the tissue and its microenvironment where the tumor originates. As an example, down regulation of miR-504 was reported in hypopharyngeal squamous cell carcinoma (Kikkawa et al., 2014), while down regulation of miR-380-5p was observed in majority of the OSCC samples compared to the matched leukoplakia or dysplasia samples (Cervigne et al., 2009). In the present study, miR-380-5p was observed to be significantly down regulated in OSCC compared to controls, whereas there was no statistically significant difference in the expression of miR-504. This suggests that miR-380-5p and miR-504 may not have a role in suppressing p53 in the context of oral carcinoma.

The candidates miR-34a and miR-143 indirectly regulate $\mathrm{p} 53$ and are further controlled by the transcriptional activity of p53 thus forming a feedback loop (He et al., 2007; Yamakuchi et al., 2008; Zhang et al., 2013a). In response to DNA damage and oncogenic stress, p53 induces the expression of the pro-apoptotic miR-34 family (Chang et al., 2007; Raver-Shapira et al., 2007; Hermeking, 2010). Therefore, miR-34 family members are expressed at very low levels in several cancers (Bommer et al., 2007; Chang et al., 2007; Tazawa et al., 2007) including OSCC (Scapoli et al., 2010). Specifically, miR-34a targets not only SIRT1, a nicotinamide adenine dinucleotide (NAD+)-dependent deacetylase which represses p53 activity by deacetylation of the protein (Yamakuchi et al., 2008), but also MDM4, another negative regulator of p53 (Mandke et al., 2012). On the other hand, miR-143 targets MDM2, which negatively controls the stability and transcriptional activity of p53. Similar to miR-34a, miR-143 which resides at chromosome $5 \mathrm{q}$, is often down regulated or deleted in a number of malignancies (Lui et al., 2007; Volinia et al., 2010; Zhang et al., 2013b; Ng et al., 2014). Moreover, miR-143 was found to be down regulated in OSCC animal model and in human head and neck squamous cell carcinoma (HNSCC) (Yu et al., 2009; Hui et al., 2010). Supporting the tumor suppressor activity of miR-34a and miR-143, we observed their down regulation in OSCC. Since both miRNAs target molecules which repress $\mathrm{p} 53$, their down regulation will invariably result in attenuation of p53 function, which in turn may result in reduced transcription of miR-34a and miR-143. Interestingly, we found that the expression levels of miR34a was comparatively high in patients with a history of alcohol consumption. In this context, it should be noted that treatment of human hepatocytes and cholangiocytes with ethanol induced the expression of miR-34a via hypomethylation of miR-34a promoter (Meng et al., 2012). Our observation on the differential expression of miR-34a in different tumor grades (G1, G2 and G3) and the association of miR-143 with advanced tumor size clearly needs confirmation in a larger sample size.

The gene LATS2 encodes a serine/threonine protein kinase that interacts with MDM2 thus functioning as a positive regulator of $\mathrm{p} 53$. Targeting of LATS 2 by miR-373 thus allows MDM2 to bind p53 and direct it to ubiquitin mediated degradation (Aylon et al., 2006; Lee et al., 2009). Also, miR-373 co-operates with oncogenic RAS to induce tumorigenic growth in testicular germ cell tumors 


\section{Mayakannan Manikandan et al}

(Voorhoeve et al., 2006). Contraindicating its oncogenic role, miR-373 was observed to be down regulated in oral/head and neck cancer cell lines (Tran et al., 2007), as well as in tumor tissues (Childs et al., 2009). In the present study, miR-373 was expressed in only two of the tumor samples showing regional lymph node metastasis. Keklikoglou et al. ( 2012) has previously reported that miR-373 was below detection levels in primary breast tumors when analysed by RT-qPCR, thus strengthening our observation. Finally, the p53 independent miRNA, miR-99a, was demonstrated to be consistently down regulated in HNSCC along with its family members (Wong et al., 2008; Hui et al., 2010; Scapoli et al., 2010; Lajer et al., 2011; Chen et al., 2012; Yan et al., 2012; Yen et al., 2014). Forced expression of miR-99 family members in HNSCC cell lines reduced cell proliferation and migration, paralleled by an increase in apoptosis (Chen et al., 2012). Therefore, the relatively high levels of miR-99a in T3/T4 tumors compared to T1/T2 tumors is not consistent with its established role and necessitates further validation in a larger sample size. Functional studies suggest that the miR-99 family members regulate AKT/mTOR signaling pathway by targeting insulin-like growth factor 1 receptor (IGF1R), mechanistic target of rapamycin (mTOR) and regulatory associated protein of mTOR (Raptor) (Doghman et al., 2010; Chen et al., 2012). Therefore down regulation of miR-99a, along with miR-143 that directly targets AKT (Noguchi et al., 2013), may activate the AKT/mTOR signaling pathway in OSCC samples.

In conclusion, the current pilot study provides a bird's eye view on the miRNA regulation of p53 in OSCC. The two selected miRNAs that directly regulate p53 were expressed at low levels and hence the possibility of translation repression of TP53 by miR-380-5p and miR-504 in OSCC is ruled out. However, the indirect p53 regulators, miR-34a and miR-143 was significantly reduced in OSCC while miR-373 expression was detectable in only two of the tumor samples. This suggests that p53 is subjected to attenuation by the negative regulators MDM2, MDM4 and SIRT1 in a subset of oral tumors. The down regulation of miR-99a along with miR143 additionally indicates the activation of AKT/mTOR pathway in OSCC. However, more extensive studies assessing the entire repertoire of miRNAs involved in p53 regulation are warranted to gain insight on the multiple mechanisms of p53 inactivation.

\section{Acknowledgements}

This work was supported by a grant from the Department of Biotechnology, New Delhi, (Grant No. BT/PR10023/AGR/36/27/2007) and from the Board of Research in Nuclear Sciences, Govt. of India (Grant No. 35/14/10/2014-BRNS/0210) to AKM. The authors thank the Department of Science and Technology and the University Grants Commission, New Delhi, for providing infrastructural facilities to the Department of Genetics, University of Madras, through DST-FIST \& UGC-SAP grants respectively. MM and AKDMR thank the Council of Scientific and Industrial Research, New
Delhi, for senior research fellowships. GA acknowledges the University Grants Commission, New Delhi, for the senior research fellowship.

\section{References}

Agrawal N, Frederick MJ, Pickering CR, et al (2011). Exome sequencing of head and neck squamous cell carcinoma reveals inactivating mutations in NOTCH1. Science, $\mathbf{3 3 3}$, 1154-7.

Aylon Y, Michael D, Shmueli A, et al (2006). A positive feedback loop between the $\mathrm{p} 53$ and Lats 2 tumor suppressors prevents tetraploidization. Genes Dev, 20, 2687-700.

Bartel DP(2009). MicroRNAs: target recognition and regulatory functions. Cell, 136, 215-33.

Bommer GT, Gerin I, Feng Y, et al (2007). p53-mediated activation of miRNA34 candidate tumor-suppressor genes. Curr Biol, 17, 1298-307.

Bushati N, Cohen SM (2007). microRNA functions. Annu Rev Cell Dev Biol, 23, 175-205.

Cervigne NK, Reis PP, Machado J, et al (2009). Identification of a microRNA signature associated with progression of leukoplakia to oral carcinoma. Hum Mol Genet, 18, 4818-29.

Chang SS, Jiang WW, Smith I, et al (2008). MicroRNA alterations in head and neck squamous cell carcinoma. Int J Cancer, 123, 2791-7.

Chang TC, Wentzel EA, Kent OA, et al (2007). Transactivation of miR-34a by p53 broadly influences gene expression and promotes apoptosis. Mol Cell, 26, 745-52.

Chen D, Cabay RJ, Jin Y, et al (2013). MicroRNA Deregulations in Head and Neck Squamous Cell Carcinomas. J Oral Maxillofac Res, 4, e2.

Chen Z, Jin Y, Yu D, et al (2012). Down-regulation of the microRNA-99 family members in head and neck squamous cell carcinoma. Oral Oncol, 48, 686-91.

Childs G, Fazzari M, Kung G, et al (2009). Low-level expression of microRNAs let-7d and miR-205 are prognostic markers of head and neck squamous cell carcinoma. Am J Pathol, 174, 736-45.

Dikshit R, Gupta PC, Ramasundarahettige C, et al (2012). Cancer mortality in India: a nationally representative survey. Lancet, 379, 1807-16.

Doghman M, El Wakil A, Cardinaud B, et al (2010). Regulation of insulin-like growth factor-mammalian target of rapamycin signaling by microRNA in childhood adrenocortical tumors. Cancer Res, 70, 4666-75.

Feng Z, Zhang C, Wu R, et al (2011). Tumor suppressor p53 meets microRNAs. J Mol Cell Biol, 3, 44-50.

Feng Z, Zhang H, Levine AJ, et al (2005). The coordinate regulation of the p53 and mTOR pathways in cells. Proc Natl Acad Sci U S A, 102, 8204-9.

Ferlay J, Soerjomataram I, Dikshit R, et al (2015). Cancer incidence and mortality worldwide: Sources, methods and major patterns in GLOBOCAN 2012. Int J Cancer, 136, 359-86.

Friedman RC, Farh KK, Burge CB, et al (2009). Most mammalian mRNAs are conserved targets of microRNAs. Genome Res, 19, 92-105.

He L, He X, Lowe SW, et al (2007). microRNAs join the p53 network--another piece in the tumour-suppression puzzle. Nat Rev Cancer, 7, 819-22.

Hermeking $\mathrm{H}$ (2010). The miR-34 family in cancer and apoptosis. Cell Death Differ, 17, 193-9.

Hermeking H (2012). MicroRNAs in the p53 network: micromanagement of tumour suppression. Nat Rev Cancer, 12, 613-26.

Hu W, Chan CS, Wu R, et al (2010). Negative regulation of 
Down Regulation of miR-34a and miR-143 May Indirectly Inhibit p53 in Oral Squamous Cell Carcinoma: a Pilot Study tumor suppressor p53 by microRNA miR-504. Mol Cell, 38, 689-99.

Hui AB, Lenarduzzi M, Krushel T, et al (2010). Comprehensive MicroRNA profiling for head and neck squamous cell carcinomas. Clin Cancer Res, 16, 1129-39.

India Project Team of the International Cancer Genome Consortium (2013). Mutational landscape of gingivo-buccal oral squamous cell carcinoma reveals new recurrentlymutated genes and molecular subgroups. Nat Commun, $\mathbf{4}$, 2873.

Kannan K, Munirajan AK, Krishnamurthy J, et al (1999). Low incidence of p53 mutations in betel quid and tobacco chewing-associated oral squamous carcinoma from India. Int J Oncol, 15, 1133-6.

Keklikoglou I, Koerner C, Schmidt C, et al (2012). MicroRNA-520/373 family functions as a tumor suppressor in estrogen receptor negative breast cancer by targeting NF-kappaB and TGF-beta signaling pathways. Oncogene, 31, 4150-63.

Kikkawa N, Kinoshita T, Nohata N, et al (2014). microRNA-504 inhibits cancer cell proliferation via targeting CDK6 in hypopharyngeal squamous cell carcinoma. Int J Oncol, 44, 2085-92.

Lajer CB, Nielsen FC, Friis-Hansen L, et al (2011). Different miRNA signatures of oral and pharyngeal squamous cell carcinomas: a prospective translational study. Br J Cancer, 104, 830-40.

Lane DP (1992). Cancer. p53, guardian of the genome. Nature, 358, $15-6$.

Lee KH, Goan YG, Hsiao M, et al (2009). MicroRNA-373 (miR373) post-transcriptionally regulates large tumor suppressor, homolog 2 (LATS2) and stimulates proliferation in human esophageal cancer. Exp Cell Res, 315, 2529-38.

Levine AJ, Feng Z, Mak TW, et al (2006). Coordination and communication between the p53 and IGF-1-AKT-TOR signal transduction pathways. Genes Dev, 20, 267-75.

Lewis BP, Burge CB, Bartel DP (2005). Conserved seed pairing, often flanked by adenosines, indicates that thousands of human genes are microRNA targets. Cell, 120, 15-20.

Livak KJ, Schmittgen TD (2001). Analysis of relative gene expression data using real-time quantitative PCR and the 2(-Delta Delta C(T)) Method. Methods, 25, 402-8.

Lui WO, Pourmand N, Patterson BK, et al (2007). Patterns of known and novel small RNAs in human cervical cancer. Cancer Res, 67, 6031-43.

Mandke P, Wyatt N, Fraser J, et al (2012). MicroRNA-34a modulates MDM4 expression via a target site in the open reading frame. PLoS One, 7, e42034.

Meng F, Glaser SS, Francis H, et al (2012). Epigenetic regulation of miR-34a expression in alcoholic liver injury. Am J Pathol, 181, 804-17.

Nelson KM, Weiss GJ (2008). MicroRNAs and cancer: past, present, and potential future. Mol Cancer Ther, 7, 3655-60.

Ng EK, Li R, Shin VY, et al (2014). MicroRNA-143 is downregulated in breast cancer and regulates DNA methyltransferases $3 \mathrm{~A}$ in breast cancer cells. Tumour Biol, 35, 2591-8.

Noguchi S, Yasui Y, Iwasaki J, et al (2013). Replacement treatment with microRNA-143 and -145 induces synergistic inhibition of the growth of human bladder cancer cells by regulating PI3K/Akt and MAPK signaling pathways. Cancer Lett, 328, 353-61.

Nohata N, Hanazawa T, Kinoshita T, et al (2013). MicroRNAs function as tumor suppressors or oncogenes: aberrant expression of microRNAs in head and neck squamous cell carcinoma. Auris Nasus Larynx, 40, 143-9.

Parkin DM, Bray F, Ferlay J, et al (2005). Global cancer statistics,

2002. CA Cancer J Clin, 55, 74-108.

Pickering CR, Zhang J, Yoo SY, et al (2013). Integrative genomic characterization of oral squamous cell carcinoma identifies frequent somatic drivers. Cancer Discov, 3, 770-81.

Raver-Shapira N, Marciano E, Meiri E, et al (2007). Transcriptional activation of miR-34a contributes to p53mediated apoptosis. Mol Cell, 26, 731-43.

Saranath D, Tandle AT, Teni TR, et al (1999). p53 inactivation in chewing tobacco-induced oral cancers and leukoplakias from India. Oral Oncol, 35, 242-50.

Scapoli L, Palmieri A, Lo Muzio L, et al (2010). MicroRNA expression profiling of oral carcinoma identifies new markers of tumor progression. Int J Immunopathol Pharmacol, 23, 1229-34.

Shiiba M, Uzawa K, Tanzawa H (2010). MicroRNAs in Head and Neck Squamous Cell Carcinoma (HNSCC) and Oral Squamous Cell Carcinoma (OSCC). Cancers (Basel), 2, 653-69.

Stransky N, Egloff AM, Tward AD, et al (2011). The mutational landscape of head and neck squamous cell carcinoma. Science, 333, 1157-60.

Swarbrick A, Woods SL, Shaw A, et al (2010). miR-380-5p represses p53 to control cellular survival and is associated with poor outcome in $\mathrm{MYCN}$-amplified neuroblastoma. Nat Med, 16, 1134-40.

Tazawa H, Tsuchiya N, Izumiya M, et al (2007). Tumorsuppressive miR-34a induces senescence-like growth arrest through modulation of the E2F pathway in human colon cancer cells. Proc Natl Acad Sci US A, 104, 15472-7.

Tran N, McLean T, Zhang X, et al (2007). MicroRNA expression profiles in head and neck cancer cell lines. Biochem Biophys Res Commun, 358, 12-7.

Volinia S, Galasso M, Costinean S, et al (2010). Reprogramming of miRNA networks in cancer and leukemia. Genome Res, 20, 589-99.

Voorhoeve PM, le Sage C, Schrier M, et al (2006). A genetic screen implicates miRNA-372 and miRNA-373 as oncogenes in testicular germ cell tumors. Cell, 124, 1169-81.

Wong TS, Liu XB, Wong BY, et al (2008). Mature miR-184 as Potential Oncogenic microRNA of Squamous Cell Carcinoma of Tongue. Clin Cancer Res, 14, 2588-92.

Yamakuchi M, Ferlito M, Lowenstein CJ (2008). miR-34a repression of SIRT1 regulates apoptosis. Proc Natl Acad Sci U S A, 105, 13421-6.

Yan B, Fu Q, Lai L, et al (2012). Downregulation of microRNA 99a in oral squamous cell carcinomas contributes to the growth and survival of oral cancer cells. Mol Med Rep, 6 , 675-81.

Yang MH, Lin BR, Chang CH, et al (2012). Connective tissue growth factor modulates oral squamous cell carcinoma invasion by activating a miR-504/FOXP1 signalling. Oncogene, 31, 2401-11.

Yen YC, Shiah SG, Chu HC, et al (2014). Reciprocal regulation of microRNA-99a and insulin-like growth factor I receptor signaling in oral squamous cell carcinoma cells. Mol Cancer, 13,6 .

Yu T, Wang XY, Gong RG, et al (2009). The expression profile of microRNAs in a model of 7,12-dimethyl-benz[a]anthranceinduced oral carcinogenesis in Syrian hamster. J Exp Clin Cancer Res, 28, 64.

Zanaruddin SN, Yee PS, Hor SY, et al (2013). Common oncogenic mutations are infrequent in oral squamous cell carcinoma of Asian origin. PLoS One, $\mathbf{8}, \mathrm{e} 80229$.

Zhang J, Sun Q, Zhang Z, et al (2013a). Loss of microRNA-143/145 disturbs cellular growth and apoptosis of human epithelial cancers by impairing the MDM2-p53 feedback loop. Oncogene, 32, 61-9.

Zhang N, Su Y, Xu L (2013b). Targeting PKCepsilon by miR-143 regulates cell apoptosis in lung cancer. FEBS Lett, 587, 3661-7. 